\title{
The enduring link between forest cover and rainfall: a historical perspective on science and policy discussions
}

\author{
Brett M. Bennett ${ }^{1,2^{*}}$ and Gregory A. Barton ${ }^{1,2}$
}

\begin{abstract}
Background: This article traces the history of scientific ideas connecting forest cover with rainfall to inform ongoing debates about whether forests are net users or producers of water in the hydrological cycle. Scholars of the supply-side school argue that forests are net producers and magnifiers that increase rainfall at regional scales. Supply-side scholars seek to challenge the dominance of demand-side thinking. The demand-side school emphasizes that trees are net users of water within a catchment that decrease overall water available for other users. This scientific debate has significant implications for the development of policies to manage forests and water.

Results: Scientists have debated the question of whether forests improve or worsen water balance for over two hundred years. Connections between forests and rainfall gained prominence in scientific circles during the second half of the nineteenth century and again during the past three decades. The popularity of forestrainfall connections has paralleled societal and scientific interest in anthropogenic climate change and deforestation. Theories connecting forests with rainfall peaked in popularity in the 1850s to 1880s, a period when scientists expressed alarm that deforestation caused regional declines in precipitation. Forests were understood to create rain within a locality and region. Scientific consensus shifted by the early twentieth century to the view that forests did not play a significant role in determining rainfall. The forest-rainfall connection reemerged in the 1980s alongside advances in climate modelling and growing fears of anthropogenic global warming and tropical deforestation. Using new data and theories, supply-side advocates have once again placed a strong forest-rainfall connection into scientific prominence.

Conclusion: Supply-side management policies have a checkered history that should elicit caution, while demand-side policies, which are based on almost a century of hydrological research, should not be overturned quickly in regions that face potential water scarcity before more research is conducted.
\end{abstract}

Keywords: Climate change, Environmental history, Forests, Hydrology, Rain, Water

\section{Background}

- "It may be safely assumed that forests favorably affect the meteorological conditions," Anders 1882

- "The best evidence at hand fails to show a decrease in rainfall over the United States in the last 100 years, in spite of the immense areas of forest that have been burned and cut," Pinchot 1905

\footnotetext{
*Correspondence: b.bennett@westernsydney.edu.au

${ }^{1}$ School of Humanities and Communication Arts, Western Sydney University, Locked Bag 1797, Penrith, NSW 2751, Australia

${ }^{2}$ Department of Historical Studies, Faculty of Humanities, University of Johannesburg, C-Ring 2 - Orange Block (Kingsway Campus), Corner Kingsway and University Road, Auckland Park, South Africa
}

- "A new hypothesis suggests that forest cover plays a much greater role in determining rainfall than previously recognized," Sheil and Murdiyarso 2009.

New thinking on forests and rainfall aims to overturn longstanding scientific paradigms and policies for water conservation. Ellison et al. recently made a "call to action that targets a reversal of paradigms...to one that treats the hydrologic and climate-cooling effects of trees and forests as the first order of priority" (Ellison et al. 2017). This statement represents an emergent supply-side school of hydrological thought that sees forests as "biotic pumps", "generators" or "recyclers" increasing the overall water 
balance in a region (Makarieva et al. 2006; Makarieva and Gorshkov 2007; Sheil and Murdiyarso 2009; Ellison et al. 2012; Sheil 2014).

For the past five years, supply-side school scholars have sought a "timely resolution" to end an almost two-century old debate about whether forests are net users or suppliers of water in the hydrological cycle (Ellison et al. 2012). This position challenges key tenets of demand-side thinking that have underpinned policies to regulate vegetation cover in catchments to maximize streamflow. Demandside thinking sees water as a finite ecological service that has other competing users. For instance, demand-side policies in South Africa limit afforestation in catchments with constrained water supply to provide water to other downstream users (Kruger and Bennett 2013; Bennett and Kruger 2015). These policies are based on long-term experimental and observation research projects that ran for decades and were designed specifically to inform policy on the question of forests and water supply (Bosch and Hewlett 1982; Andréassian 2004). Supply-side scholars critique this perspective for focusing narrowly on the catchment scale without properly accounting for regional and global dynamics that influence the generation of precipitation (Ellison et al. 2012).

The idea that forests modify regional hydrological cycles and climate has a long intellectual and policy history that has not been discussed by recent scholarship of the supply-side. In many respects, the mechanisms underlying past and present theories about forests and rain are strikingly similar. So too have scientists at different times advocated similar policy recommendations based on the idea that forests influence rainfall and climate. It is necessary to understand how contemporary ideas developed across time and space. A historical perspective can highlight problems that emerged in the past. It also highlights the scientific, policy and public context in which current demand-side policies developed across the twentieth century. This historical viewpoint should be considered if supply-side thinking is implemented into policy and management contexts.

\section{Methods}

This study analyzes historical and scientific literature to trace key developments in ideas and policies linking forests to rainfall and climate. In addition to identifying relevant materials in the field of environmental history, the authors used scholarly databases Google Scholar, EBSCOhost and JSTOR for articles relating to forests and rainfall from the 1800 s until the present day.

\section{Results}

\section{The history of supply-side thought}

The belief that humans can induce climate and meteorological changes by altering vegetation has appeared throughout history (Hulme 2017). In ancient Greece, Theophrastus (371-287 BCE) argued that Greece had experienced climatic change due to the draining of marshes and extension of agriculture (Glacken 1976). The link between vegetation and climate emerged elsewhere around the world at different times. It reached its greatest extent and popularity in the 1850 s to 1880 s when scientists, politicians and members of the public throughout the Western world advocated that forests influenced regional climate and rainfall (Grove 1995; Barton 2002; Davis 2007; 2016; Beattie 2011; Cushman 2011). During this age, the destruction of nature from globalization and colonialism created considerable anxieties, akin to our own fears of global warming and tropical deforestation (Beattie 2011). The belief that forests needed to be protected to stabilize climate influenced the rise of the first global environmental movement (Barton 2002) and led to the establishment of protected and productive forest areas worldwide (Bennett 2015).

An unbroken evolution of thinking on forest-rainfall connections can be traced from the late 1400 s to the present. The idea that forests strongly influence rainfall emerged in the early modern era (1450-1750) in response to the Scientific Revolution and European exploration and expansion throughout the world (Grove 1995). The Genoese-Spanish explorer Christopher Columbus (1451-1506) reasoned that the intense mid-day rains in the American tropics were induced by the dense tropical forest foliage which had a high moisture content that was recycled. He also argued that deforestation in the tropics led to declining rainfall. Grove argues that Columbus's ideas reflected a widely-held belief that deforestation in the Canary Islands, Madeira and Azores Islands during European colonization caused a decline in overall rainfall. Naturalists in the 1600s and 1700s argued similarly that deforestation on the islands of St. Helena and Mauritius and in the Caribbean led to similar rainfall declines. Despite emergent lines of thinking, there was no naturalist consensus on the forest coverrainfall debate prior to the first quarter of the nineteenth century. Though many warned that deforestation led to declining rainfall other commentators, such as GeorgesLouis Leclerc (1707-1788) and Thomas Jefferson (17431826), saw deforestation as making a positive contribution to climate by moderating temperatures.

A more scientific and modern theory of deforestationinduced climate change can be traced back to Alexander von Humboldt (1769-1859), a wealthy Prussian naturalist. As Humboldt travelled extensively through the Americas from 1799 to 1804, he observed a connection between forest cover and rainfall (Cushman 2011). He argued that the declining water level of Lake Valencia, located in modern day Venezuela, occurred when settlers created agricultural plantations out of native forest. Humboldt's thoughts 
gained popularity because they fit within an existing line of thinking going back to at least the late 1400s. He had scientific credibility because his detailed observations in Latin America appeared to be proven by later events and were then propagated through an extensive network of patronage. In one prominent example, Humboldt encouraged Jean-Baptiste Boussingault (1801-1887) to revisit Lake Valencia to see whether the lake had risen or fallen. On arrival, Boussingault found extensive secondary growth forest caused by a slave uprising during the Revolution that destroyed the plantations. That the water level seemingly rose when the forests grew back confirmed Humboldt's ideas in the minds of many at the time, although it is now generally recognized that the lake levels had fluctuated due to secular variation in rainfall.

The forest-rainfall connection gained a new international authority in 1864 after George Perkins Marsh (1801-1882), a well-respected American former senator and man of letters, published an authoritative review of literature on the relationship between forests, rainfall and climate. Marsh's Man and Nature: Or, Physical Geography as Modified by Human Action (Marsh 1864) was the single most influential book in shaping attitudes towards forest and climate during the second half of the nineteenth century. The belief that humans throughout history had changed regional climate due to deforestation was a centerpiece of his book. His biographer Lowenthal notes that the book, "ushered in a revolution in the way people conceived their relations with the earth" (Lowenthal 2000).

Marsh wrote that "a majority of the foresters and physicists who have studied the question are of opinion that in many, if not all cases, the destruction of the woods has been followed by a diminution of the annual quantity of rain and dew" (Marsh 1864). Marsh argued that trees acted as great pumps, generating water for the atmosphere: "the vapour carried off by transpiration greatly exceeds the quantity of water absorbed by the foliage from the atmosphere, and the amount, if any, carried back to the ground by the roots" (Marsh 1864). Trees influenced local temperature by absorbing heat and producing "refrigeration", thus cooling local climates. Forest soils also absorbed more moisture than non-forest soils, creating more water for catchments and allowing for trees to return this moisture to the atmosphere.

Marsh acknowledged the many unknowns. Definitively measuring a link between forests and climate beyond a highly-localized area (such as under the canopy) proved elusive. Marsh admitted that, "we cannot measure the value of any one of these elements in climatic disturbance, raising or lowering of temperatures, increase or diminution of humidity". It was unknown whether transpiration fell locally or was carried by wind far away
(Marsh 1864). He did not think that forests had an influence on climate at the global scale: "it does not seem probable that the forests sensibly affect the total quantity of precipitation, or the general mean of the atmospheric temperature of the globe" (Marsh 1864). Even with these uncertainties, he still justified forest conservation on a precautionary principle: "When, therefore, man destroyed these natural harmonizers of climatic discords, he sacrificed an important conservative power" (Marsh 1864).

Marsh's views reflected the consensus among foresters, a professional group that had significant influence over government and public views of forests at the time. Foresters brought concerns of deforestation-induced climate change with them throughout the world when they moved to take up the first wave of forestry appointments in European colonies (Barton 2002; Davis 2007; Beattie 2011). Foresters lobbied governments to set aside large swathes of common lands into forest reserves to be controlled by professional foresters through a policy framework that allowed for certain multiple-uses, such as wood collection and even preservation, but which was primarily oriented to sustaining timber production (Bennett 2015). Foresters did not see harvesting to be antithetical to climatic preservation because foresters aimed to take no more from the forest than grew back so total forest cover would stay the same or even grow in size.

The idea that forests influenced rainfall and climate became the subject of considerable popular discussion in newspapers, popular books and parliaments. Classics experts pointed out that Biblical and ancient examples showed that the Middle East had more forests and rain in the past than present (Barton 2002; Davis 2007, 2016). To elites with little scientific literacy, classics provided compelling evidences. Journalism also played an important role in public perception-for example, 77\% of newspaper articles in Australia from the 1860s to the 1930 s that discussed the question of whether forests influence climate saw forests as having an influence on climate and rain (Legg 2014).

The link between forest cover and water yield reached its peak popularity in the 1870 s and 1880 s before suffering scientific and popular criticism that led to its decline globally in the 1900s and on. These criticisms are discussed in the next section. The forest-rainfall connection continued to remain popular among many former colonial foresters and advocates of forest protection. St. Richard Barbe Baker, the popular forestry author and founder of Men of the Trees, promoted this idea tirelessly from the 1940s to 1980s (Baker 1944, 1970). Environmental campaigners have sometimes used this argument to argue against the excessive harvesting of timber. In the 1990s, leaders of the Chipko movement in India argued that deforestation led to declines in rainfall (Hamilton 1992). However, the idea held little sway in 
scientific circles until there was a revival in the 1980s and 1990s.

\section{Scientific and popular criticism of forest cover water yield} The idea that forests produced rain received criticism even at its peak popularity. Marsh noted, "Unfortunately, the evidence is conflicting in tendency, and sometimes equivocal in interpretation" (Marsh 1864). The influential American meteorologist, General A.W. Greely (18441935), himself a believer in the influence of forests on climate, expressed similar concerns in his influential 1888 book American Weather: "The question of the influence of vegetation and forests upon rain fall is a vexed one, and from its character is not susceptible of positive proof or disproof" (From Legg 2014).

The emergence of climatology and more advanced meteorological studies steadily undermined the idea that vegetation influenced climate. The emergence of the field of climatology with the 1883 publication of Julius von Hann's (1839-1921) seminal Handbook of Climatology (Handbuch der Klimatologie) led researchers to emphasize the physical and global drivers of climate while downplaying the importance of forests in climate systems (Edwards 2013). Hann questioned the validity of climatic measurements, especially those showing temperature change or increases/decreases in rain, based on methodological grounds. Rainfall shifts could be better explained as secular variations rather than as being caused by changes to forests. This viewpoint influenced mainstream climatological and metrological positions for most of the twentieth century.

The actions of some foresters did little to help the profession sustain the idea that forests influence climate against new thinking in climatology and meteorology. Colonial foresters in North Africa, India, South Africa and Australia embarked on extensive tree-planting campaigns in the 1860 s to 1880 s to push back deserts and increase rain (Davis 2007; Beattie 2011; Bennett and Kruger 2015). The idea that trees could improve climate helped to spur European settlement and colonization in regions such as the arid interior of South Australia or the Karoo in South Africa. Attempts to develop agriculture and timber plantations in the interior of South Australia succeeded briefly in the 1860 s and 1870s due to a temporary increase in rainfall, but this period came to sudden closure when rainfall returned to the historical norm and plummeted (Meinig 1988). It became apparent that without water most imported tree species would not grow, let alone change the climate. From Algeria to Australia, forestry departments wrote off efforts to improve deserts and arid lands and turned their attention to areas of higher productivity.

Foresters in the 1890s began to quit justifying policy based on the forest-rainfall connection. Beattie argues that foresters in the United States, Australia, and New Zealand switched their policy focus to the hydrological importance of trees because increasingly discredited forest-rainfall connection threatened their position as policy and public opinion leaders (Beattie 2011). Foresters maintained their control over forestry by shifting towards views that were still widely held by the public and could be experimentally tested. The view that trees and forests played a positive role in the hydrological cycle then dominated forest policy in countries such as the United States, India and South Africa during the early twentieth century.

The forest-hydrological link came under growing criticism. The first text book written on forests and climate, Forest Influences, noted that foresters had "only a hazy conception of what is meant by forest influences, watershed management, and protection" (Kittredge 1948). French engineers had since the 1840s questioned claims made by foresters about the hydrological and climatological influence of forests (Andréassian 2004). Engineers pointed to contradictory evidence and a lack of experimental or observational results. They argued that foresters lacked proper data to justify protecting forests in catchments to conserve water or to increase supply. It took almost a hundred years before a proper experiment was designed to examine these claims.

In South Africa, the debate about forests and their influence on water supply and rainfall led the government to establish a hydrological research station on the Eerste River in the Jonkershoek Valley in 1935 near the city of Stellenbosch to measure how planted alien trees influenced streamflow dynamics compared with indigenous Fynbos heathland. (Bennett and Kruger 2013, 2015; Kruger and Bennett 2013). Its director Christiaan Wicht (1908-1978) designed a paired catchment experiment. The only earlier paired catchment at Wagon Wheel Gap in Colorado, USA, focused on sub-alpine forests (Saberwal 1998). Findings from this site were not seen to be applicable to tropical, subtropical or extratropical conditions. In 1949, Wicht wrote up his initial findings in the report Forestry and Water Supplies in South Africa (Wicht 1949). Wicht argued the loss of water in the catchment occurred via transpiration from trees. These findings, along with research (some done in collaboration) at Coweta in Georgia, USA, led many foresters and hydrologists to change their views on the hydrological impact of forests (Bosch and Hewlett 1982). The idea that forests are users of finite water within catchments informs forest policy in many arid and temperate regions of the world, especially those that experience intermittent rainfall, severe low seasonal streamflows or water shortages.

Hydrological researchers in the 1960s and 1970s concluded that forests did not influence rainfall. H.C. 
Peirera, then one of the world's renowned hydrologists, wrote in his 1973 book on water in temperate and climate regions: "There is no corresponding evidence as to any effects of forests on the occurrence of rainfall" (cited from Hamilton 1992). The Amazon and "cloud forests" on mountains that captured oceanic moisture were perhaps the two exceptions to these rules.

Some forest-climate research continued into the mid-twentieth century, but it occurred under a more limited form focused on "local peculiarities" in climate such as on mountains, in valleys and within forest canopy (Geiger 1951). Rudolph Geiger's (18941981) pioneering research in Germany on climates near the ground, which was translated from German into English in 1950, established the field of microclimatology as a significant field of international research. Geiger's work pointed to distinct microclimates determined by canopy cover, species composition, rain interception and dew formation, among other influences (Geiger 1950). Research on large forests suggested that established canopies and forest ecosystems could have a positive influence on the water balance (Biel 1961). The view that mountain forests generate water and rain recurred in popular campaigns and writing. Viviroli et al. (2007) extended this into a metaphor by calling mountains "water towers for humanity".

The idea that vegetation influenced rainfall and climate continued to shape environmental policy in Africa and Asia despite international trends in hydrology and forestry downplaying the influence of vegetation on regional rainfall and climate. Fears about desertification and desiccation became pronounced in India and Africa in the 1930s because of concerns raised by droughts during the Depression (Saberwal 1998; Beinart 2003). Colonial officials saw denudation of soil and destruction of vegetation as a key cause of social, ecological and climatic problems. These scientists took their views with them as they took up positions at the end of empire in international development agencies, such as United Nations Educational, Scientific and Cultural Organization (UNESCO), the UN's Food and Agricultural Organization (FAO), World Bank and other national overseas development programs (Hodge 2010; Barton 2010; Davis 2016).

Concerns about desiccation and desertification gained international attention in the early 1970 s because of the devastating famine in the Sahel caused by a half-decade drought from 1968 to 1974. Many experts attributed the famine to human-induced desertification caused by overgrazing, overpopulation and denuded vegetation (Davis 2016). The MIT climate researcher Jule Charney (1917-1981) turned his attention to desertification in the Sahel. His research focused on albedo, the reflectivity of light off surfaces. Albedo is lowest in a forest, which absorbs up to $80 \%$ of sunlight, thus warming surface temperatures, and is highest in a desert or snowpack, which reflects upwards of $80 \%$ of light, which cools due to the lack of retained solar radiation. Charney argued that the denudation of vegetation by grazing and human activity increased albedo, which led to cooling via a loss of radiative energy; the decline in energy ultimately weakened the Hadley circulation, which brought rain to the Sahel; this process therefore caused a decline in rainfall (Charney 1975; Charney et al. 1977). The whole concept of desertification-from its human causes to its ecological and climatological effects-are, like the aformentioned forest-hydrological connection, contested but nonetheless still pervasive in public and policy discussions (Davis 2016).

\section{Revival}

There was a revival of interest in forest-climate influences starting in the mid-to late 1970s brought on by growing concern about anthropogenic climate change and deforestation, advances in climate modelling and continued interest in desertification and albedo. Rapid developments in climate modelling in the late 1970s to mid-1980s renewed interest in the relationship between forests, rainfall and temperature, especially in the wet tropics. In 1979, the first World Climate Conference emphasized the importance of forests as shapers of climate, but participants noted that there was a lack of data on how forests influenced climate (Edwards 2013). Early climate models raised numerous possibilities. Models were divided on whether the removal of tropical forests would modify global and regional climate either by increasing surface albedo, potentially cooling the earth, or increasing $\mathrm{CO}_{2}$ into the atmosphere, and warming it via greenhouse effect (Henderson-Sellers and Gornitz 1984).

Initially researchers theorized that tropical deforestation would lead to regional and global cooling with corresponding declines in rainfall. A key Nature paper in 1975 concluded that increased albedo caused by deforestation would reduce surface temperature, reduce evaporation and rainfall, weaken the Hadley circulation and cool the middle and upper tropical troposphere (Potter et al. 1975). Carl Sagan et al. in 1979 argued in Science that albedo caused by deforestation and other humaninfluences, such as fire, caused desertification that had potentially cooled the earth over time. Sagan noted, "during the past several thousand years the earth's temperatures could have been depressed by about $1 \mathrm{~K}$, due primarily to desertification, which might have significantly augmented natural processes in causing the present climate to be about 1 to $2 \mathrm{~K}$ cooler than the climatic optimum of several thousand years ago" (Sagan et al. 1979). Sagan suggested that to achieve an imagined 
climatic optimum deforestation in the Amazon "may even be desirable, as a counterbalance to greenhouse heating of the earth", though they noted, "it would seem prudent, on an issue of possible global importance, to study its implications in some detail before proceeding unilaterally" (Sagan et al. 1979). Sagan's view was promptly challenged (Potter et al. 1981).

The idea that deforestation in the Amazon would create a global climate optimum was dropped when evidence and new thinking suggested tropical deforestation could lead to warmer temperatures and less rain. Climate models and the earliest experiments in the 1980s suggested that any cooling caused by increased surface albedo would be counterbalanced by decreased cooling because of lower evaporation rates (Henderson-Sellers and Gornitz 1984; Dickinson and Henderson-Sellers 1988). In the late 1980s, the earliest detailed micrometeorological measurements in central Amazonian rainforests in Brazil produced measurements confirming global models that showed a net increase in temperature due to declining cooling caused by the loss of evaporation (Shuttleworth 1988; Gash and Shuttleworth 1991). This perspective has been confirmed and is recognized widely by researchers working in the field of climate change (Bonan 2008; van der Ent et al. 2010).

Albedo has remained a process of interest to climate researchers, but its overall importance in climate models declined due to advances in measurement of other sources of warming. Albedo came to prominence in the 1970s because of satellite imagery which showed striking changes in landscape caused by humans (Nicolson 2011). The results of research on albedo are somewhat contradictory due to factors such as latitude, snow cover, the overall carbon stocks of forests and forest-induced evaporation. The most up-to-date research suggests that deforestation-induced albedo would have opposing outcomes depending on latitude and landscape. Tropical deforestation is seen to produce a net warming because of increased carbon released from the forests, reduction in evaporative cooling and lowered cloud albedo. The transformation of grasslands to forest might also decrease albedo thus inducing warming (Bond 2016). In the higher Northern latitudes, deforestation is believed to produce cooling due to the increase of albedo with more snow-cover, and would offset the warming effect of carbon emissions (Bonan 2008; Jiao et al. 2017).

Growing interest in climate, especially the idea that greenhouse gases could increase global temperature, encouraged researchers in several fields to begin thinking about how deforestation, forest protection and afforestation influenced global climate, especially anthropogenic warming. In 1979, a National Research Council team led by Jule Charney (the same Charney who published key studies on desertification and albedo) first predicted that a doubling of $\mathrm{CO}_{2}$ would likely increase the global temperature from $2^{\circ}$ to $3.5{ }^{\circ} \mathrm{C}$, with an error of $1.5^{\circ}$. Advances in modelling and measurement in the 1980s and 1990s allowed for researchers to understand diverse forest dynamics (e.g. carbon absorption, carbon emissions, ozone emissions, albedo, influence on rain) and to incorporate these processes and data into increasingly sophisticated regional and global climate scenarios.

Scientists began to raise alarms that the loss of trees through tropical deforestation would increase greenhouse gases. Whereas earlier theories of forests and climate tended to deny the global importance of forests on climate (Marsh 1864), advances in global climate modelling encouraged researchers to begin thinking about how forests influenced global climate. Advances in climate and vegetation modelling, prediction and data production and sharing have given greater power to environmental predictions, especially those associated with global warming. When global warming became an “actionable crisis" (Edwards 2013: 361), it cracked open the door for the re-entry of the forest-rainfall connection.

Forests once again became the central focus of global policy discussion in the 1990 s due to international concerns about $\mathrm{CO}_{2}$ emissions. In 1992, the Kyoto Protocol promoted the idea that protecting tropical forests from deforestation could help to slow the release of $\mathrm{CO}_{2}$ into the atmosphere and thus lessen predicted climate warming (Hulme 2017). In 2008, three organizations (FAO, UNDP, and UNEP) within the United Nations established the Program on Reducing Emissions from Deforestation and Forest Degradation (REDD) to stop forest loss to decrease carbon emissions from forests and to sequester airborne carbon stocks. A considerable amount of work been done to measure carbon storage of forests. Forests are now estimated to produce approximately $12-20 \%$ of yearly carbon emissions because of deforestation and the establishment of agriculture and human infrastructure (Van Der Werf et al. 2009, with correction of $12 \%$ from an original estimate of $20 \%$ ) while they absorb upwards of 1 / 3rd to 1/4th of anthropogenic emissions (Reich 2011; Bellassen and Luyssaert 2014).

The emergence of the supply-side school within the past decade reflects advances in regional climate modelling, new ideas in atmospheric physics and more accurate measurement of water molecules through the hydrological cycle. Prominent scholars within the supply-side school posit that forests influence climate and weather at regional and global scales in ways that have not been properly acknowledged by climate policy or modelling. The strongest advocates of supply-side thinking challenge both the carbon-centric priority of forest policy and the demandside perspective of hydrology. Ellison et al. write: "For 
reasons of sustainability, carbon storage must remain a secondary, though valuable, by-product" (Ellison et al. 2017). There is disagreement on how much forests influence hydrological cycles (see van der Ent et al. 2012), but still most researchers in the field believe that it is prudent to preserve forests for their climatic stabilizing role. Despite uncertainty, supply-side scholars argue that the climatic influences of forests should underpin global forest policy. This viewpoint is having its influence on policies from the European Union to the Amazon. A 2012 report for the European Union from researchers at the British Met Office argues that forests "play a major role in the atmospheric circulation and the water cycle on land and may have a role in mitigating regional climate, desertification and water security problems" (Sanderson et al. 2012).

\section{Discussion}

This discussion points to potential downsides to policies based on supply-side thinking while encouraging more research in the area. More research is required to establish a firmer basis for the claims made by supply-side scholars. Even scholars whose work has been used to support supply-side thinking argue that existing work is "simplistic" and "exaggerates the role of the forest in the hydrological cycle" (van der Ent et al. 2012). It is simply too early to call for a paradigm change. Forest and water conservation policy throughout much of the world has been guided by decades of careful analysis, experimentation and debate. This careful, long-term research has not yet been done by the supply-side school.

There is a real potential that, if applied too broadly, the supply-side perspective could be used to justify treeplanting in areas with limited water supply. Ellison et al. support tree planting in Spain to increase precipitation (Ellison et al. 2012). This view runs contrary to a significant body of hydrological evidence from Spain (not to mention studies from comparable climates elsewhere in the world) that shows strong correlations between increased forest-cover and decreased water-supply (see for instance Buendia et al. 2016; Gallart and Llorens 2003). Supply-side thinking has the potential to reinforce calls for widespread tree-planting in Africa. Hydrologists and ecologists are already alarmed at proposals such as the World Resource Institute goal to "restore" 100 million hectares in Africa by planting trees because they fear these efforts will cause decreases in streamflow, as they have done in other regions (Jackson et al. 2005; Pittock et al. 2013; Bond 2016). Supply-side thinkers have mentioned some of these concerns (Ellison et al. 2012), but have said little about what regions would need revisions of policy and what regions should keep existing protocols.

Premature calls for supply-side policy creates the risk that the public and policy makers will be led by instinct rather than science. Many have continued to view forests as having positive overall impacts on rainfall and water balance even though there is a significant body of experimental and observational hydrology suggesting to the contrary (Calder 2002). The history of forestry shows that there has been a tendency to over-emphasize the benefits of supply-side policies while downplaying the potential social, economic or environmental issues associated with them (Bennett 2015). Humans are culturally and perhaps even genetically predisposed to environments with trees. Decades of studies suggest that people from diverse backgrounds and cultures prefer green environments with trees, whether in the context of savanna, urban environments or forests (Purcell et al. 2001; Van den Berg et al. 2007; Carrus et al. 2015). This pro-tree bias can tilt public attitudes on climate and biodiversity management towards forest policies that may have negative consequences for other ecosystems and water users.

The longstanding tendency to see trees as climatic and hydrological regulators explains the recurrence of certain forestry narratives. Andréassian argues "the ghost of deforestation seems to appear every time a new catastrophic flood or drought occurs" (Andréassian 2004). A study of desertification by Davis comes to similar conclusions: "academic research has shown for more than 25 years that estimates of desertification have been significantly exaggerated and that most of the world's dryland are not being invaded by spreading deserts caused by deforestation, burning, and overgrazing as claimed since the word was first coined nearly one hundred years ago" (Davis 2016).

Some ecologists and social scientists warn about creating a world where forests are more strictly protected than other ecosystem types. Efforts to preserve or conserve forests have ecological and social consequences. People who live in or utilize forests face the prospect of being removed or having livelihoods curtailed if global policies encourage states to centralize forest management to protect forests (Agrawal et al. 2011). Protecting forests may lead to biodiversity losses in other ecosystems. Ideally, the conservation of one species or ecosystem should not come at the expense of another. Unfortunately, there is evidence to show that preservation in one place may lead to unexpected destruction and consequences in another. For instance, the popularity of protecting rainforest in Brazil has possibly encouraged the destruction of the diverse Cerado grasslands (Bond 2016). It is easier to convince middle class people in suburbs to give money to save rainforest than grasslands because grasses do not seem to elicit the same level of emotional response (Bond and Parr 2010). 


\section{Conclusions}

If the supply-side view is correct, an increase in forest cover will allow us to live in a world with more plentiful water where we can better handle predicted climate changes. There is, at the same time, a risk that policy makers, if influenced by this thinking, might downplay the potential negative impacts. Over a century of careful research and experimentation has been implemented to devise evidence-based policy, and it would be a mistake to overturn a century of painstaking research without more solid evidence. If policies are hastily imposed, and a policy framework based on over a century of hydrological research is overturned, there is a distinct possibility that supply-side policies may cause more social, ecological, economic and hydrological problems than they solve. History offers insights into potential pitfalls and explains why demand-side policies remain the dominant paradigm for many regions of the world. Ideas and policies should change, but only when there is robust evidence and greater consensus.

\section{Abbreviations}

FAO: Food and Agricultural Organization; REDD: Reducing Emissions from Deforestation and Forest Degradation; UNESCO: United Nations Educational, Scientific and Cultural Organization

\section{Acknowledgements}

The authors would like to thank the three anonymous reviewers for their comments. The authors would like to thank Forest Ecosystems and Beijing Forestry University.

\section{Funding}

The authors received funding from the Australian Research Council for the Discovery Project grant, "Saving the world the first time: global climate theory and desiccation 1765-1960" DP110104024.

\section{Availability of data and materials}

Not Applicable.

\section{Authors' contributions}

$\mathrm{BMB}$ is the lead author of the paper. Both authors read and approved the final manuscript.

\section{Ethics approval and consent to participate}

Not Applicable.

\section{Consent for publication}

Not Applicable.

\section{Competing interests}

The authors declare that they have no competing interests.

Received: 20 October 2017 Accepted: 27 November 2017

Published online: 08 February 2018

\section{References}

Agrawal A, Nepstad D, Chhatre A (2011) Reducing emissions from deforestation and Forest degradation. Annu Rev Environ Resour 36:373-396

Anders JM (1882) Forests: their influence upon climate and rainfall. Am Nat 16(1):19-30

Andréassian V (2004) Waters and forests: from historical controversy to scientific debate. J Hydrol 291:1-27

Baker RSB (1944) | planted trees. Lutterwoth Press, London and Redhill

Baker RSB (1970) My life, my trees. Lutterworth Press, London
Barton GA (2002) Empire forestry and the origins of environmentalism. Cambridge University Press, Cambridge

Barton GA (2010) Environmentalism, development and British policy in the Middle East 1945-65. J Imp Commonw Hist 38(4):619-639

Beattie J (2011) Empire and environmental anxiety: health, science, art and conservation in South Asia and Australasia, 1800-1920. Palgrave Macmillan, Basingstoke

Beinart W (2003) The rise of conservation in South Africa: settlers, livestock and the environment. Oxford University Press, Oxford, pp 1770-1950

Bellassen V, Luyssaert S (2014) Carbon sequestration: managing forests in uncertain times. Nature 506:153-155

Bennett BM (2015) Plantations and protected areas: a global history of forest management. The MIT Press, Cambridge

Bennett BM, Kruger FJ (2013) Ecology, forestry and the debate over exotic trees in South Africa. J Hist Geogr 42:100-109

Bennett BM, Kruger FJ (2015) Forestry and water conservation in South Africa: history, science and policy. ANU Press, Canberra

Biel ER (1961) Microclimate, bioclimatology, and notes on comparative dynamics climatology. Am Sci 49(3):326-357

Bonan GB (2008) Forests and climate change: Forcings, feedbacks, and the climate benefits of forests. Science 320:1444-1449

Bond WJ (2016) Ancient grasslands at risk. Science 351:120-122

Bond WJ, Parr CL (2010) Beyond the forest edge: ecology, diversity and conservation of the grassy biomes. Biol Conserv 143(10):2395-2404

Bosch JM, Hewlett JD (1982) A review of catchment experiments to determine the effect of vegetation changes on water yield and evapotranspiration. J Hydrol 55:3-23

Buendia C, Batalla RJ, Sabater S, Palau A, Marcé R (2016) Runoff trends driven by climate and afforestation in a Pyrenean Basin. Land Degrad Dev 27(3):823-838

Calder IR (2002) Forests and hydrological services: reconciling public and science perceptions. Land Use Water Resour 2:1-12

Carrus G, Scopelliti M, Lafortezza R, Colangelo G, Ferrini F, Salbitano F, Agrimi M, Portoghesi L, Semenzato P, Sanesi G (2015) Go greener, feel better? The positive effects of biodiversity on the well-being of individuals visiting urban and peri-urban green areas. Landscape Urban Plan 134:221-228

Charney J, Quirk WJ, Chow S, Kornfield J (1977) A comparative study of the effects of albedo change on drought in semi-arid regions. J Atmos Sci 34:1366-1385

Charney JG (1975) Dynamics of deserts and drought in the Sahel. Q J Roy Meteor Soc 101(428):193-202

Cushman GT (2011) Humboldtian science, creole meteorology, and the discovery of human-caused climate change in South America. Osiris 26:16-44

Davis DK (2007) Resurrecting the granary of Rome environmental history and French colonial expansion in North Africa. Ohio University Press, Athens

Davis DK (2016) The arid lands: history, power, knowledge. The MIT Press, Cambridge

Dickinson RE, Henderson-Sellers A (1988) Modelling tropical deforestation: a study of GCM land-surface parameterizations. Q J Roy Meteor Soc $114: 439-462$

Edwards PN (2013) A vast machine: computer models, climate data, and the politics of global warming. MIT Press, Cambridge

Ellison D, Futter MN, Bishop K (2012) On the forest cover-water yield debate: from demand- to supply-side thinking. Glob Chang Biol 18(3):806-820

Ellison D, Morris CE, Locatelli B, Sheil D, Cohen J, Murdiyarso D, Gutierrez V, van Noordwijk M, Creed IF, Pokorny J, Gaveau D, Spracklen DV, Tobella AB, Ilstedt U, Teuling AJ, Gebrehiwot SG, Sands DC, Muys B, Verbist B, Springgay E, Sugandi Y, Sullivan CA (2017) Trees, forests and water: cool insights for a hot world. Global Environ Chang 43:51-61

Gallart F, Llorens P (2003) Catchment management under environmental change: impact of land cover change on water resources. Water Int 28(3):334-340

Gash JH, Shuttleworth WJ (1991) Tropical deforestation: albedo and the surfaceenergy balance. Clim Chang 19:123-133

Geiger R (1950) The climate near the ground. Harvard University Press, Cambridge

Geiger R (1951) Microclimatology. In: Malone TF (ed) Compendium of meteorology. American Meteorological Society, Boston

Glacken C (1976) Traces on the Rhodeian shore: nature and culture in western through from ancient times to the end of the eighteenth century. University of California Press, Berkeley and Los Angeles 
Grove R (1995) Green imperialism: colonial expansion, tropical island Edens and the origins of environmentalism 1600-1860. Cambridge University Press, Cambridge

Hamilton LS (1992) The protective role of mountain forests. GeoJournal 27(1):13-22

Henderson-Sellers A, Gornitz V (1984) Possible climatic impacts of land cover Transforma- tions, with particular emphasis on tropical deforestation. Clim Chang 6:231-258

Hodge J (2010) British colonial expertise, postcolonial careering and the early history of international development. J Mod Eur Hist 8:24-46

Hulme M (2017) Weathered: cultures of climate. Sage, London

Jackson RB, Jobbagy EG, Avissar R, Roy SB, Barrett DJ, Cook CW, Farley KA, le Maitre DC, McCarl BA, Murray BC (2005) Trading water for carbon with biological carbon sequestration. Science 310:1944-1947

Jiao T, Williams CA, Ghimire B, Masek J, Gao F, Schaaf C (2017) Global climate forcing from albedo change caused by large-scale deforestation and reforestation: quantification and attribution of geographic variation. Clim Chang 142:463-476

Kittredge J (1948) Forest influences: the effects of woody vegetation on climate, water and soil, with applications to the conservation of water and the control of floods and erosion. McGraw-Hill, New York

Kruger FJ, Bennett BM (2013) Wood and water: an historical assessment of South Africa's past and present forestry policies as they relate to water conservation. T Roy Soc S Afr 68(3):163-174

Legg S (2014) Debating the climatological role of forests in Australia, 1827-1949. In: Beattie J, Henry M, O'Gorman E (eds) Climate, science, and colonization: histories from Australia and New Zealand. Palgrave Macmillan, New York, pp 119-136

Lowenthal D (2000) George Perkins marsh: prophet of conservation. University of Washington Press, Seattle

Makarieva AM, Gorshkov VG (2007) Biotic pump of atmospheric moisture as driver of the hydrological cycle on land. Hydrol Earth Syst Scs 11(2): 1013-1033

Makarieva AM, Gorshkov VG, Li BL (2006) Conservation of water cycle on land via restoration of natural closed-canopy forests: implications for regional landscape planning. Ecol Res 21(6):897-906

Marsh GP (1864) Man and nature. C Scribner, New York

Meinig DW (1988) On the margins of the good earth the south Australian wheat frontier 1869-1884. South Australia Govt Printer, Netley

Nicolson S (2011) Dryland climatology. Cambridge University Press, Cambridge

Pinchot G (1905) A primer on forestry. US Government Printing Office, Washington DC

Pittock J, Hussey K, McGlennon S (2013) Australian climate, energy and water policies: conflicts and synergies. Aust Geogr 44:3-22. https://doi.org/10.1080/ 00049182.2013 .765345

Potter GL, Ellsaesser HW, MacCracken MC, Ellis JS (1981) Albedo change by man: test of climatic effects. Nature 291:47-49

Potter GL, Ellsaesser HW, MacCracken MC, Luther FM (1975) Possible climatic impact of tropical deforestation. Nature 258:697-698

Purcell T, Peron E, Berto R (2001) Why do preferences differ between scene types? Environ Behav 33(1):93-106

Reich P (2011) Biogeochemistry: taking stock of forest carbon. Nat Clim Chang 1:346-347. https://doi.org/10.1038/nclimate1233

Saberwal VK (1998) Science and the Desiccationist discourse of the 20th century. Environ Hist 4(3):309-343

Sagan C, Toon OB, Pollack JB (1979) Anthropogenic albedo changes and the Earth's climate. Science 206:1363-1368

Sanderson M, Pope E, Santini M, Mercogliano P, Montesarchio M (2012) Influences of EU forests on weather patterns. Met Office, Devon

Sheil D (2014) How plants water our planet: advances and imperatives. Trends Plant Sci 19(4):209-211

Sheil D, Murdiyarso D (2009) How forests attract rain: an examination of a new hypothesis. Bioscience 59(4):341-347

Shuttleworth WJ (1988) Evapotranspiration from Amazonian rain Forest. Proc Roy Soc B 233:321-346

Van den Berg AE, Hartig T, Staats H (2007) Preference for nature in urbanized societies: stress, restoration, and the pursuit of sustainability. Soc Issues 63:79-96

Van der Ent RJ, Coenders-Gerrits AMJ, Nikoli R, HHG S (2012) The importance of proper hydrology in the forest cover-water yield debate: commentary on Ellison et al. (2012). Glob Chang Biol 18(9):2677-2680 van der Ent RJ, Savenije HHG, Schaefli B, Steele-Dunne SC (2010) Origin and fate of atmospheric moisture over continents. Water Resour Res 46:W09525. https://doi.org/10.1029/2010WR009127

Van Der Werf GR, Morton DC, Defries RS, Olivier JGJ, Kasibhatla PS, Jackson RB, Collatz GJ, Randerson JT (2009) $\mathrm{CO}_{2}$ emissions from forest loss. Nat Geosci 2(11):737-738

Viviroli D, Dürr HH, Messerli B, Meybeck M, Weingartner R (2007) Mountains of the world, water towers for humanity: typology, mapping, and global significance. Water Resour Res 43(7):w07447. https://doi.org/10.1029/ 2006WR005653

Wicht CL (1949) Forestry and water supplies in South Africa Pretoria. Department of Forestry, South Africa

\section{Submit your manuscript to a SpringerOpen ${ }^{\circ}$ journal and benefit from:}

- Convenient online submission

- Rigorous peer review

- Open access: articles freely available online

- High visibility within the field

- Retaining the copyright to your article

Submit your next manuscript at $>$ springeropen.com 